Article

\title{
Wind Power Pricing Game Strategy under the China's Market Trading Mechanism
}

\author{
Fugui Dong ${ }^{\circledR}$, Xiaohui Ding * and Lei Shi *(i) \\ School of Economics and Management, North China Electric Power University, Beijing 102206, China \\ * Correspondence: susan1221@ncepu.edu.cn (X.D.); shilei0317@ncepu.edu.cn (L.S.)
}

Received: 31 July 2019; Accepted: 2 September 2019; Published: 7 September 2019

\begin{abstract}
Wind power has become the main power generation method in China's clean energy power generation because of its clean and high efficiency, as well as its high power utilization rate. The research on its pricing mechanism has also become the main research focus of the wind power industry. However, wind power pricing is still at the stage of price benchmarking and no market mechanism has been introduced in China. There are still much research on the pricing mechanism of wind power for us to study. In this paper, the Kernel method is used to distribute wind power income. On the basis of the distribution result, considering the contract execution risk of wind power, cooperative game theory and the Shapley value method are used to redistribute the revenue of wind power connected to power grid. Based on the characteristics of alliance members, ANP (Analytic Network Process) was used to modify the apportioned benefits to obtain the benefit distribution method that was more in line with the interest demands of members, and an example was analyzed. The wind power pricing model based on the cooperative game established in this paper can guarantee the smooth operation of the alliance, reach the pareto optimum, and improve the activity of the wind power market. It will effectively shorten the negotiation time, and reduce the transaction cost and the uncertainty of the wind power transaction.
\end{abstract}

Keywords: wind power pricing; kernel method; game strategy; market trading mechanism

\section{Introduction}

Energy is not only the economic lifeline of a country, but also an important strategic resource. In recent years, with the continuous increase of government policy support, the wind energy industry has shown rapid development. In 2018, China's cumulative installed capacity wind power exceeded 200 million kW, creating a huge post-operation market for wind power. Although China has made great achievements in wind power development, it still adopts the benchmark electricity price mechanism in the wind power pricing mechanism. The difference between the benchmark electricity price and the electricity price of a desulfurization coal-fired unit is subsidized by the Renewable Energy Development Fund. The fund comes mainly from additional revenue from renewable electricity tariffs levied on electricity users. Under this model, renewable energy power generation companies have long capital recovery cycles and large capital pressures. In addition, the self-supplied power plants are heavily in arrears with renewable energy tariffs. The amount of renewable energy tariffs actually collected by the Ministry of Finance is much smaller than the theoretical amount, which has led to a large gap in China's renewable energy development funds. With the expansion of renewable energy grid-connected capacity year by year, the gap of renewable energy funds will become larger and larger, and become a most important factor limiting the development of new energy in China. In order to better solve the problem of wind power pricing, on the basis of reading related literature, this paper analyzes the current wind power pricing mechanism at home and abroad, using the method of nucleoli of the profit distribution models of the bilateral trade mode, so as to determine the wind power electricity 
price, using cooperative game theory and the Shapley value for adjustment and improvement of profit distribution. Afterwards, the ANP method is introduced to adjust the pricing model, and prove the validity of the model through examples.

Therefore, on the basis of studying the existing wind power pricing mechanism in China, it is necessary to discuss the dynamic pricing theory suitable for wind power under the electricity market trading mechanism based on the new electricity reform policy and game theory. The innovation of this paper lies in using game theory, ANP, and other theoretical methods to construct the wind power pricing strategy under the market trading mechanism. Through the contract price determination mechanism simulated by the kernel method and according to the contribution level of each participant to make a reasonable profit distribution, we effectively mobilize the enthusiasm of both parties involved in the transaction. Based on the risk assessment results of bilateral trading participants and their trading objects, the Shapley value method is used to allocate the cooperative benefits, which effectively urges traders, especially those with large demand, to make reasonable offers, and therefore improves trading efficiency. It can not only put forward a more realistic pricing model, but also help the development of wind power in China.

\section{Literature Review}

\subsection{Research Status of Foreign Wind Power Pricing Mechanism}

Among renewable energy sources, wind energy is attracting attention as a new energy source with the most development scale and commercial development potential. Osorio, G.J.et al. proposed a flexible security-constrained program to schedule supply-side and demand-side via an optimal pricing and incentive scheme [1]. Fang, X. et al. proposed a new electricity market-clearing mechanism based on locational marginal prices (LMPs) for pricing uncertain generation and load. Compared with traditional LMPs, the proposed U-LMP (uncertainty contained locational marginal price) formulation includes two new uncertainty components: a transmission line overload uncertainty price and a generation violation uncertainty price [2]. Gersema $\mathrm{G}$ et al. studied the equilibrium pricing model of wind power futures. They put forward a representative of the two agents of the equilibrium pricing model to analyze the equilibrium price and the mechanism behind the futures risk premium, as well as a random model of calibration and simulation of wind power, electricity price, electricity demand, and other relevant sources of uncertainty, then a case study was carried out on the German market [3]. Bolinger $\mathrm{M}$ et al. analyzed the development of wind power pricing policies implemented in countries such as the United States, Germany, and Denmark. Afterwards, they summarized the types of wind power price policies in various countries, including government planning, fixed electricity prices, capital subsidies, tax incentives, renewable energy quota systems, green electricity prices, cost control, and bidding prices. They believe that the most important pricing mechanism in the early stage of wind power development is the fixed price pricing mechanism, while the tax regulation and financial subsidies also have a major impact on the development of the wind power industry [4-6]. Tomiyama, $K$. et al. proposed a model prediction controller based on the real-time pricing problem of power system. The real-time pricing operation balances the demand and supply of electricity other than renewable energy to maximize the interests of consumers and suppliers [7]. Bruck, M. et al. analyzed the impact of wind power price and cost from the perspective of risk, and considered the impact of risk management on wind power pricing policy in the power market $[8,9]$. Considering the need to reserve or balance services, Sarfati, M. et al. proposed a probabilistic pricing model. It enables efficient operation and investment of ramp-service providers in power systems with large amounts of wind or solar power [10]. Dai, Z. et al. proposed an integrated cost allocation method based on optimal power flow tracking based on the advantages and disadvantages of the present cost allocation method and marginal cost pricing. Under the premise of ensuring the equilibrium of reactive power price, the optimal power flow distribution of reactive power is realized with the minimum integration cost and wind power integration [11]. Benth, F.E. et al. proposed a wind power futures pricing model in 
the context of wind power production index modeling, and the pricing problem of European wind energy futures is solved by using Fourier technology [12].

\subsection{Research Status of Wind Power Pricing Mechanism in China}

With the smooth implementation of the new power reform policy, China's wind power pricing mechanism also ushered in new reform. Yuping Wang et al.'s analysis of the composition and influence factors of wind power electricity price, electricity price and the relationship between the policy environment, and the use setting scheme incentive policy of cost benefit analysis and evaluation method has been clear about the need to reduce the cost, reduce the barriers to progress, and reduce electricity prices. They also recommended that China's current wind power electricity price policy put forward an appropriate extension of the repayment period, provide exemptions from VAT(value added tax), and adjust the wind power investment and conventional energy power investment profit ratio, as well as other policy recommendations [13-17]. Fugui Dong et al. proposed that under the premise of solving the problem of wind curtailment, appropriately promoting power consumption and renewable energy policy reform, from a Feed-in-Tariff (FiT) to a Renewable Portfolio Standard (RPS), are effective means to promote the development of wind power generation in China [18]. Lihua Sun et al. analyzed the components and influencing factors of wind power prices based on the wind power cost [19]. Yuan Li highlighted the impact of interest cost and tax cost on wind power cost [20]. In view of the proposed RPS policy in 2019, Fugui Dong et al. proposed policy recommendations based on the possible problems of the current policy and designed an incremental electricity price supplementary policy to improve the possibility of successful implementation of the RPS policy [21]. Zhengming Wang et al. combined the specific wind power project investment level and wind resource level to calculate the electricity price [22]. Qiuju Zhang et al. discussed the green electricity price into grid mechanism in China and in other countries, and then put forward the measure of a green electricity pricing model. By combining this measure with a practical calculation, the results show that without considering the premise of environmental cost and environmental benefits, the green energy benchmarking electricity price is far below the thermal power price [23]. Jizhen Liu et al. believed that the current implementation of the wind power sub-regional fixed electricity price system does not dynamically reflect changes in wind power costs, resulting in a waste of financial resources, and more importantly, does not give a specific accounting process for power generation costs and reasonable profits. They proposed a wind power pricing mechanism based on wind power cost and thermal power profit, and introduced the implementation process of the proposed electricity price mechanism by taking a thermal power plant and a wind farm as an example, and verified the rationality of the electricity price mechanism [24]. On the basis of analyzing the experience of Australia's trans-regional power transmission, Xiao Gao puts forward his trans-regional power transmission policy, which has reference significance for China's trans-regional power transmission pricing mechanism, and puts forward his own suggestions [25]. Yang Li provided a comprehensive summary of renewable energy electricity pricing policy and a cost-sharing system and analyzed the current relevant price policy and the associated dynamic adjustment mechanism and subsidies money debt. In addition, he combined this analysis with a background of electric power system reform and the marketization of electricity prices, put forward a series to promote the development of renewable energy electricity price policy, and provided suggestions for electric power system reform involving better use of price policy to promote the healthy development of renewable energy [26]. By studying the latest progress of the UK's electricity market reform and the pricing mechanisms for nuclear power including the contract for difference, Shubiao Yin et al. put forward suggestions for various institutional arrangements, market supervision, and electricity pricing management system in light of the problems existing in China's new energy industry such as "abandoning wind", "abandoning light" and "abandoning nuclear" [27]. With the background of the new situation and on the basis of analyzing the characteristics of the electric power marketing mode and the new electricity price system, Min Su has studied the innovative electric power marketing mode and the new electricity price, respectively [28]. By analyzing peak 
valley price and its mechanism, Yantao Wang et al. established a comprehensive income model of peak valley pricing based on wind power consumption. Through the analysis of calculation examples, it is concluded that the model which implements time-of-use prices in the sales side and online side simultaneously can not only realize multi-party benefits, but also can improve the capacity of wind power accommodation. And raising the peak valley price ratio appropriately can optimize the multi-party benefits and reduce the abandoned wind rate [29].

Based on research in China and in other countries, it can be found that although there are many theoretical studies on wind power pricing, most of the wind power pricing mechanisms are from the perspective of wind power cost management and risk management, and lack of consideration of wind power load, interest appeals, and other factors that affect wind power prices. In addition, most of the above literatures regard the buyers and sellers as having non-cooperative game relationships, under which the wind power suppliers will satisfy the highest bidder to the greatest extent, resulting in insufficient power purchase by the lower bidder or only high cost power purchase and increased costs. Considering the minimization of their own costs, the purchasing electric power supplier will give priority to the one with the lowest price, which will also lead to the loss of profits of the purchasing electric power supplier with higher quotation, unfair distribution of benefits, and the inability to mobilize the enthusiasm of all participants, which is not conducive to the improvement of social welfare.

Therefore, based on the wind power load demand, this paper introduces the idea of a cooperative game, where the buyers and sellers negotiate and formulate the contract electricity price according to their respective contributions and inputs, and establish the wind power pricing mechanism and profit distribution model under a cooperative trading mode. Through the calculation example, the contract price of electricity and profit distribution results that meet the maximization of both parties' interests can be obtained to ensure the stable operation of the power system and provide a reference for national wind power pricing policy.

\section{Wind Power Trading Model}

Due to the cyclical nature of wind power generation, it predicts good results in monthly load forecasting and annual load forecasting. Because of the volatility of wind power generation, its prediction in real-time forecasting is not as good as its medium- and long-term forecasts. Combining the advantages and characteristics of the bilateral trading mode in the field of medium and long-term electricity trading, this paper builds a wind power pricing mechanism based on game theory and nucleolar theory underpinned by the bilateral trading model.

Bilateral transactions refer to the way in which power supply and demand sides (power plants, wholesalers, retailers, and various brokerage companies) negotiate in a power market to reach bilateral contracts (including trading power and prices). Due to the existence of predictable medium and long-term power consumption and unpredictable real-time electricity in the electricity market, under the bilateral transaction-based power trading mode, there are contract transactions and real-time bidding transactions. Among them, bilateral contract transactions account for more than $80 \%$ of power transactions, which is a guarantee to ensure the stability and reliability of the power market, and which is also the main form of power trading. The existence of real-time power mainly stems from the shortage of bilateral contracts, which can solve the real-time demand of the system. However, due to rapid changes in demand, the price of electricity changes rapidly and the electricity is scattered, meaning it is not conducive to fast transactions.

In bilateral contract transactions, the electricity supplier and the electricity purchaser negotiate the transaction object and the transaction plan through the power exchange center or over-the-counter transaction, and sign a bilateral transaction contract. After signing the contract, the dispatching agency will modify and confirm the contract according to the line constraints and will supervise its execution. The grid company is responsible for the safe power transmission of the grid, while the power trading center is responsible for settlement and announcement of the trading information of the trading entity 
to improve market transparency. A schematic diagram of the bilateral trading model is shown in Figure 1.

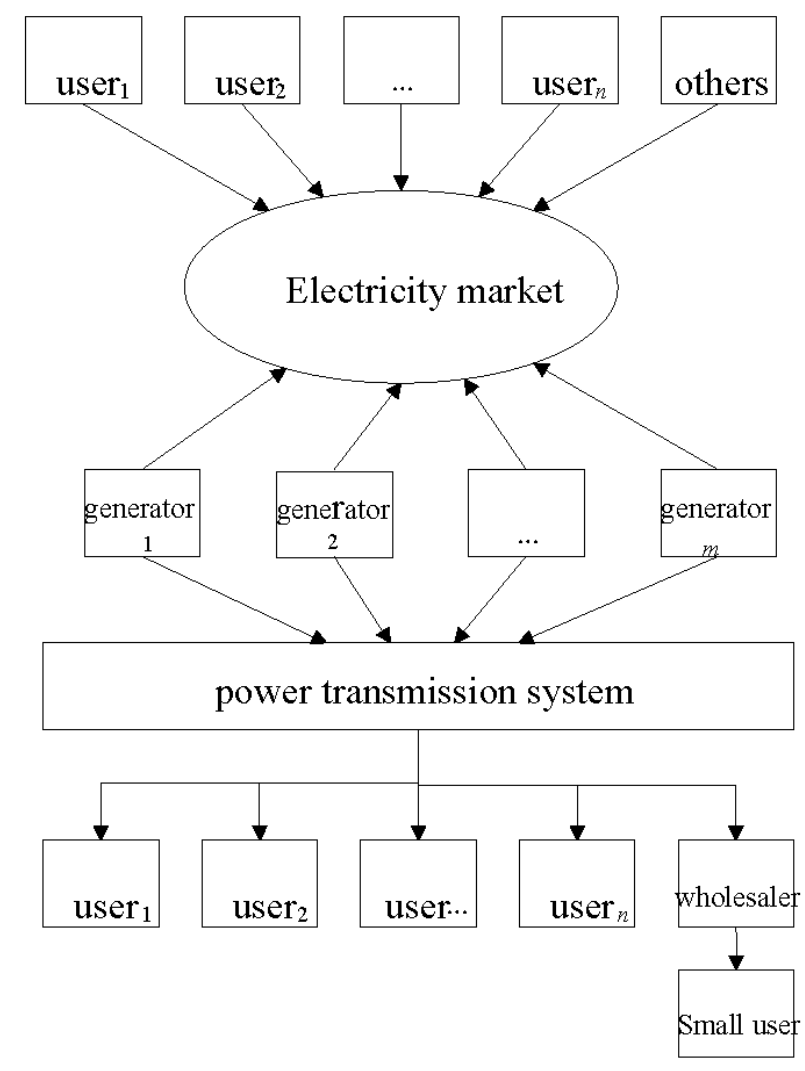

Figure 1. Bilateral transaction simulation.

\section{Wind Power Pricing Based on Cooperative Game}

At present, China mainly implements regional fixed electricity prices for renewable energy. This system refers to a price policy where the on-grid electricity price of renewable energy is designated by the government, and power grid enterprises are obliged to purchase all the electricity generated by the new energy generation mode at the price set by the government. Although this pricing system can reduce the potential risks for new energy investors, and the policy implementation process is simple, the fixed electricity price system is not flexible enough to adjust the electricity price in a timely manner to obtain the maximum benefits of different resource conditions, no project costs, and different technical types of renewable energy projects. Unlike general commodities, wind power has great uncertainty. Existing benchmark pricing cannot meet the demand of the wind power market, so it is more appropriate to use cooperative game theory to discuss the bilateral electricity pricing mechanism. At the same time, in the course of the operation of the bilateral wind power trading market, the transaction subject and transaction form are characterized by diversification and complexity. And the nucleolar theory guarantees that any participant in the multiplayer cooperative game still obtains the most profitable or smallest loss result in its most unfavorable distribution plan. Therefore, in order to improve the activity of the wind power market and ensure the smooth operation of the transaction, this paper uses the nucleolar theory to simulate the contract price determination mechanism based on the choice of transaction objects in the bilateral wind power market.

\subsection{Introduction to Nucleolar Theory}

Nucleolar theory is a concept proposed by Schmeidler in 1969 that is located in the non-empty kernel median. The main definitions are as follows. 
Definition 1. For two different s-dimensional vectors $g$ and $h$, if there is a relationship of $1 \leq f \leq s$ in the first different component as shown in Equation (1), the vector $g$ is said to be smaller than the vector $h$ in lexicographic order. Recorded as $h>\operatorname{lex}(g)$.

$$
\begin{aligned}
& g_{i}=h_{i} \\
& g_{f}<h_{f}, i=1,2, \cdots, f-1
\end{aligned}
$$

where $g_{i}$ and $h_{i}$ are the ith vectors of vectors $g$ and $h$, and $g_{f}$ and $h_{f}$ are the fth vectors of vectors $g$ and $h$, respectively.

Definition 2. In an n-player game $(N, V)$, for Union $M$ and allocation $c=\left(c_{1}, c_{2}, \cdots, c_{n}\right)$ the expectation of Union $M$ under allocation $c$ is as shown in Equation (2). The greater the expectation, the greater the willingness of members of Alliance $M$ to form a coalition, and the greater degree to which the members of the alliance are satisfied with a payment vector.

$$
e(M, c)=V(M)-\sum_{i \in M} c_{i}
$$

where $(M, c)$ is the expectation of alliance $M$ under allocation $c, V(M)$ is the total return of alliance $M$, and $\sum_{i \in M} c_{i}$ is the assigned sum of alliance member $i$.

Definition 3. In an n-person game, let $N$ be the set of players in the game. For all payment vector sets $C$, the nucleoli $\psi(C)$ of the game is still a set, and the set contains all the daisy-ordered minimum payment vectors, $c \in C$ as shown in Equation (3).

$$
\psi(C)=\{c \in C \mid \Lambda(d) \geq \operatorname{lex} \Lambda(c), \forall d \in C\}
$$

where $\Lambda(c)$ and $\Lambda(d)$ are the expectations of assigning the union $M$ under $c$, there are $2^{n}$ in total, and these components are arranged in the order of no increase.

In the process of solving the nucleoli problem, the nucleolar problem can be transformed into a linear programming problem as shown in Equation (4), and then solved by Matlab software.

$$
\begin{gathered}
\text { s.t. } \sum_{i \in M} c_{i}-V(M) \geq \xi \\
\sum_{i \in N} c_{i}=V(N) \\
\forall \xi<0
\end{gathered}
$$

where $V(N)$ is the total return of all members.

\subsection{Wind Power Pricing Mechanism Based on Cooperative Game Theory}

In the bilateral trading market, according to the number of power suppliers and purchasers, it can be divided into a one-to-many bilateral trading mode and a many-to-many trading mode.

\subsubsection{One-to-Many Bilateral Contract Trading Mechanism}

When there is only one power producer and multiple electricity purchasers or one electricity purchaser and multiple power producers in the bilateral trading market, the bilateral contract transaction is a one-to-many trading mode. This paper studies the construction of a one-to-many trading mechanism from the perspective of the only power producer who purchases using e-commerce. A one-to-many trading mechanism is divided into independent and cross-trading based on whether the trading volume can be split. Independent trading means that the power producer only signs a bilateral transaction contract with a certain electricity purchaser at the same time. Since there is only one power supplier and one electricity purchaser in the transaction process, it can also be called a bilateral independent transaction. When a power producer chooses to cooperate with different electricity purchasers, the transaction form is called a bilateral cross transaction. 
(a) Bilateral independent transaction

When generator A chooses a partner to participate in bilateral transactions, it will select the target to be cooperated in the collection of electricity supplier $\left\{B_{1}, B_{2}, \cdots B_{n}\right\} . \quad A$ and $B_{j}$ will determine the cooperation partner and the cooperative electricity price through the interest game. Let $L=\left\{A, B_{1}, B_{2}, \cdots B_{n}\right\}$ be the cooperative alliance, the alliance member quoted as $P^{(1)}=\left\{P_{A}, P_{B_{1}}, P_{B_{2}}, \cdots, P_{B_{n}}\right\}$, then the cooperation profit of the electricity supplier $A$ and the purchaser $B_{j}$ is $\pi_{j}=\left(P_{B_{j}}-P_{A}\right) \cdot Q$, when $P_{B_{j}} \leq P_{A}, \pi_{j}=0$. The total profit of the supplier $A$ and the purchaser is shown in Equation (5).

$$
\begin{aligned}
& V\left(A B^{(2)}\right)=\max \pi_{j} \\
& B^{(2)} \subseteq B^{(1)}
\end{aligned}
$$

Among them, $B^{(1)}$ represents the purchasers who can participate in the contract, and $B^{(2)}$ represents the purchasers who finally participates in the transaction.

In this alliance, the power supplier A will automatically choose the partner so as to maximize its profits. The nucleolar method can be used to obtain the benefit distribution of the participants, and the members with zero interest will not be able to participate. Then, the contract price $P$ can be calculated from Formula (6), where $Q$ is the contract quantity of electricity and the profit of the supplier $A$ will gradually increase as the number of purchasers increases.

$$
\left\{\begin{array}{l}
\pi_{A}=\left(P-P_{A}\right) \cdot Q \\
\pi_{B_{j}}=\left(P_{B_{j}}-P\right) \cdot Q
\end{array}\right.
$$

(b) Bilateral cross transaction

Bilateral cross transaction means that when the power provided by generator $A$ can meet the needs of multiple power purchasers, in order to maximize their own interests, they will consider signing contracts with multiple purchasers at the same time.

$L=\left\{A, B_{1}, B_{2}, \cdots, B_{n}\right\}$ is still a cooperative alliance. The alliance member's quotation is still $P^{(1)}=\left\{P_{A}, P_{B_{1}}, P_{B_{2}}, \cdots, P_{B_{n}}\right\}$. The cooperation profit of the supplier $A$ and the purchaser $B_{j}$ is $\pi_{j}=\left(P_{B_{j}}-P_{A}\right) \cdot Q_{j} \cdot Q_{j}$ is the contract quantity of electricity between $A$ and the purchaser. When $P_{B_{j}} \leq$ $P_{A}, \pi_{j}=0$.

The total profit of the supplier $A$ and the electricity purchaser is shown in Equation (7), and the price profit formula is shown in Equation (8).

$$
\begin{gathered}
V\left(A B^{(2)}\right)=\sum_{j=1}^{s} \pi_{j} \\
B^{(2)} \subseteq B^{(1)} \\
\left\{\begin{array}{l}
\pi_{A}=\sum_{j=1}^{s}\left(P_{A B_{j}}-P_{A}\right) \cdot Q_{B_{j}} \\
\pi_{B_{j}}=\left(P_{B_{j}}-P_{A B_{j}}\right) \cdot Q_{B_{j}}
\end{array}\right.
\end{gathered}
$$

Among them, $B^{(1)}$ is the purchaser who signed the contract, $s$ is the quantity of the electricity purchaser in the collection $B^{(2)}$, and $P_{A B_{j}}$ is the contract price of the generator $A$ and the purchaser $B_{j}$.

\subsubsection{Many-to-Many Bilateral Contract Trading Mechanism}

When both the generators and the purchasers in the bilateral market are not unique, the transaction process will be more complicated than the one-to-many model. In the case of many-to-many, if it is still differentiated according to whether the transaction power is divided, it can be divided into multi-party independent transactions and multi-party cross transactions. Multi-party independent trading means that any generator can independently meet the electricity demand of a certain electricity 
supplier, so any power producer can only sign a bilateral trading contract with a certain electricity supplier at the same time, and multi-party cross-trade refers to the transaction. Any generator can simultaneously enter into a deal with multiple purchasers. The multi-party cross-transaction shows that both the power producer and the electricity purchaser have the right to choose to cooperate with multiple trading partners at the same time. In the transaction contract, the seller, the buyer, and the transaction are not the only three variables.

(a) Multi-party independent trading mode

For the bilateral power trading mode in which the power producer and the electricity purchaser are not unique, the transaction result is the same as the one-to-many model, and the Pareto optimal principle must be realized, that is, the object and the power of the transaction in the bilateral transaction realize the principle of collective rationality.

In the multi-party independent transaction mode, let $\Delta P$ be the set of quotation differences between traders, which can be arranged in order of $\left\{\Delta P_{1}, \Delta P_{2}, \cdots, \Delta P_{h}\right\}$ from large to small, where $h \leq m, h \leq n, \Delta P_{1}=\max \Delta P_{A_{i} B_{j}}$ and the transaction objects are not repeated. The total profit of the generator and the electricity supplier is shown in Equation (9).

$$
\begin{aligned}
& V\left(A^{(2)} B^{(2)}\right)=\sum_{\Delta P_{k}^{(2)} \in \Delta P^{(2)}}\left(\Delta P_{k}^{(2)} \cdot Q_{k}\right) \\
& A^{(2)} \subseteq A^{(1)}, B^{(2)} \subseteq B^{(1)}, \Delta P^{(2)} \subseteq \Delta P^{(1)} \\
& k \leq h \leq m, k \leq h \leq n
\end{aligned}
$$

where, $\Delta P^{(1)}$ represents the set of quotation differences between the parties involved in the contract signing, $A^{(1)}$ and $B^{(1)}$ represent the generators and purchasers participating in the contract, $\Delta P_{k}^{(2)}$ represents the spread formed by the coordinator and the purchaser, $Q_{k}$ is the amount of electricity, $m$ is the number of traders participating in the trade, and $n$ is the number of all traders. The price profit formula obtained by the nucleolar metod is shown in Equation (10).

$$
\left\{\begin{array}{l}
\pi_{A_{i}}=\left(P_{A_{i} B_{j}}-P_{A_{i}}\right) \cdot Q_{A_{i} B_{j}} \\
\pi_{B_{j}}=\left(P_{B_{j}}-P_{A_{i} B_{j}}\right) \cdot Q_{A_{i} B_{j}} \\
\Delta P_{A_{i} B_{j}} \in \Delta P^{(1)} \\
i \in\{1,2, \cdots, m\}, j \in\{1,2, \cdots, n\}
\end{array}\right.
$$

Among them, $A_{i}$ and $B_{j}$ are the two sides of the transaction when the transaction spread is $\Delta P_{A_{i} B_{j}}$, and $P_{A_{i} B_{j}}$ is the transaction price.

(b) Multi-party cross transaction mode

In the multi-party cross-transaction mode, both generators and purchasers can choose to work with multiple trading partners at the same time. Therefore, there are many forms of performance in the transaction contract, which are manifested in three forms: cross-transaction of the seller, cross-transaction of the buyer and cross-trading by both the buyer and the seller. This paper takes the cross-transaction between the two parties as an example. Let the price difference $\Delta P$ between traders be arranged in descending order, $\Delta P_{1}, \Delta P_{2}, \cdots, \Delta P_{h}$. Different from multi-party independent transactions, in a multi-party cross-trade, because an independent trader cannot meet the demand for bilateral trading power, the same trader will repeat, resulting in the transaction being non-unique in 
the signed bilateral contract. When using the nucleolar method to distribute profits, the profit formula is shown in Equation (11).

$$
\begin{aligned}
& V\left(A^{(2)} B^{(2)}\right)=\sum_{\Delta P_{k}^{(2)} \in \Delta P^{(2)}}\left(\Delta P_{k}^{(2)} \cdot Q_{k}\right) \\
& A^{(2)} \subseteq A^{(1)}, B^{(2)} \subseteq B^{(1)}, \Delta P^{(2)} \subseteq \Delta P^{(1)} \\
& k \leq h \leq m \cdot n
\end{aligned}
$$

Although Equation (11) is similar to Equation (9), since the two sides of the transaction can be repeated in the multi-party cross transaction, the value range of $k$ changes, which is larger than that in the case of the independent transaction mode. The two parties will trade in the order of the price difference. If the transaction volume between $A_{i}$ and $B_{j}$ meets the requirements of one trader, the trader will no longer participate in the transaction, and the profit of his trading with other partners is zero. Calculate the profit distribution value based on the nucleolus method, and bring the value into the price profit formula as shown in Equation (12) to obtain the contract price.

$$
\left\{\begin{array}{l}
\pi_{A_{i}}=\sum_{\Delta P_{A_{i} B_{j}} \in \Delta P^{(1)}}\left(P_{A_{i} B_{j}}-P_{A_{i}}\right) \cdot Q_{A_{i} B_{j}} \\
\pi_{B_{j}}=\sum_{\Delta P_{A_{i} B_{j}} \in \Delta P^{(1)}}\left(P_{B_{j}}-P_{A_{i} B_{j}}\right) \cdot Q_{A_{i} B_{j}} \\
\forall i \in\{1,2, \cdots, m\}, \forall j \in\{1,2, \cdots, n\}
\end{array}\right.
$$

It can be seen that the result of the profit distribution by the nucleolus method can satisfy the Pareto optimal principle while ensuring the smooth operation of the alliance, and greatly shortens the negotiation time of the transaction, reduces the transaction cost, and reduces the uncertainty of the transaction. Therefore, it is very appropriate to apply the nucleolus method to the two trading mechanisms of wind power. Although the core solution of cooperative game can provide satisfactory results for the participants of the alliance, it may be difficult to achieve or sometimes there is no core solution in the process of solving the core solution, which is also the deficiency of the current cooperative game in the application of wind power pricing.

\subsection{Cooperative Profit Distribution Based on Improved Shapley Value}

Due to the uncertainty of wind power generation, there will be a certain degree of trading risk in the process of wind power trading. In order to avoid the transaction losses caused by this risk, both power suppliers and purchasers are more inclined to cooperate with more stable and powerful parties. Since the wind power trading market is different from the ordinary commodity trading market and is delivered in real time, the risk of trading is greater and more complicated. In order to comprehensively consider the influencing factors (power supply risk, compliance risk and user risk) affecting the transaction risk of the bilateral power market and the complex relationship among various factors, this paper will use the ANP method to realize the risk assessment of bilateral trading participants on their trading objects. Based on the results of the risk assessment, the Shapley value is used to distribute the cooperative income.

As a solution of cooperative game, Shapley value method has feasibility and uniqueness, and can provide good economic signals for participants of cooperative game. The Shapley value measures the status of each participant in the alliance according to their marginal contribution to the alliance, thus allocating the total profits (or total savings) of the alliance. Since the calculation process of Shapley value method is easy to understand and the allocation result conforms to the economic principle, it can be accepted by the participants when it is applied to solve the cooperative game problem in the power market.

Set the power supplier as $A$ and the power purchase as $\left\{B_{1}, B_{2}, \cdots, B_{n}\right\}$. Power supplier $A$ uses ANP to select the trading partner with which it works in $\left\{B_{1}, B_{2}, \cdots, B_{n}\right\}$ and determine the contract quantity of electricity to be cooperating with it. It is assumed that the power supplier $A$ estimates the 
transaction risk set of the individual cooperation with the purchaser through the ANP as $\Upsilon, \Upsilon_{i} \in \Upsilon$, and ranks the risk value from low to high to obtain $\Upsilon_{1} \leq \Upsilon_{2} \leq \cdots \leq \Upsilon_{n}$, then the power supplier will cooperate with a purchaser with a low risk factor and a total risk value that does not exceed a certain threshold $\Upsilon$ In this paper, the threshold $\Upsilon$ is set to $50 \%$, that is, only the purchaser who satisfies the Formula (13) can conduct bilateral transactions with the power supplier $A$.

$$
\left\{\begin{array}{l}
\sum_{i=1}^{j} \Upsilon_{i} \leq 50 \% \\
i<j \\
\Upsilon_{i} \in\left\{\Upsilon_{1}, \Upsilon_{2}, \cdots, \Upsilon_{n}\right\} \\
\Upsilon_{j} \in\left\{\Upsilon_{1}, \Upsilon_{2}, \cdots, \Upsilon_{n}\right\}
\end{array}\right.
$$

Let the purchaser who will participate in the transaction be $B_{i}$, and $Q$ is the total transaction power. The electricity that the supplier $A$ and the purchaser $B_{i}$ will trade is shown in Equation (14). The greater the risk of cooperation, the smaller the contract quantity of electricity.

$$
Q_{A B_{i}}=\frac{\frac{1}{\Upsilon_{i}}}{\sum_{i=1}^{m} \frac{1}{\Upsilon_{i}}} \cdot Q
$$

Since the average marginal and marginal contribution of the Shapley method is determined by the spread and the volume of the transaction, the Shapley value method can effectively promote the reasonable quotation of the trader, especially the one with greater demand, and improve the transaction efficiency. In 1953, Shapley proposed the concept of the value of the n-person strategy from the perspective of axiomatization, namely the Shapley value. Because the Shapley value method guarantees the existence and uniqueness of the result, it is widely used to solve the problem of income distribution in n-person cooperation. In this study, we use Equations (15) to solve the distribution profits of electricity purchasers and other alliance members. Where $\mathrm{m}$ is the number of participants in $M, V(\varnothing=0)$.

$$
\phi_{i}=\sum_{M \subseteq N \backslash\{i\}} \frac{|M| !(|n-m-1|) !}{n !} \cdot[V(M \cup i)-V(M)]
$$

Let $L=\left\{A, B_{1}, B_{2}, \cdots, B_{n}\right\}$ be a cooperative alliance between wind power generators and purchasers. The alliance member's quotation is still $P^{(1)}=\left\{P_{A}, P_{B_{1}}, P_{B_{2}}, \cdots, P_{B_{n}}\right\}$, then the cooperation profit between power supplier $A$ and purchaser $B_{j}$ is $\pi_{j}=\left(P_{B_{j}}-P_{A}\right) \cdot Q_{j}$, and $Q_{j}$ is the amount of electricity that purchaser $B_{j}$ expects to purchase. When $P_{B_{j}} \leq P_{A}, \pi_{j}=0$, the total profit of the supplier $A$ and the purchaser is shown in Equation (16), and the price profit formula is as shown in Equation (17). Among them, $B^{(1)}$ is the purchaser who participated in the contract, and $s$ is the number of purchasers in the set $B^{(2)}$.

The contract price $P_{A B_{j}}$ of the generator $A$ and the purchaser $B_{j}$ is obtained by bringing the income distributions $\pi_{A}$ and $\pi_{B_{j}}$ of all participating trading members obtained by the Shapley value method into the Formula (17).

$$
\begin{aligned}
& V\left(A B^{(2)}\right)=\sum_{j=1}^{s} \pi_{j} \\
& B_{j} \in B^{(2)} \\
& B^{(2)} \subseteq B^{(1)}
\end{aligned}
$$




$$
\left\{\begin{array}{l}
\pi_{A}=\sum_{j=1, j \in B^{(1)}}^{s}\left(P_{A B_{j}}-P_{A}\right) \cdot Q_{B_{j}} \\
\pi_{B_{j}}=\left(P_{B_{j}}-P_{A B_{j}}\right) \cdot Q_{B_{j}}
\end{array}\right.
$$

The traditional Shapley value theory assumes that the willingness of the players to form each alliance are the same, but this assumption is contrary to the fact that the members of the alliance face different factors such as technology and their innovation ability in the cooperation process. In fact, traders will use their own advantages in the process of power trading to maximize their profits. Power traders who are faced with greater risks will try to obtain greater profits under the threat of withdrawing from the cooperative alliance, while those who are faced with less risks will choose to provide part of their profits to those who are faced with greater risks, so as to ensure the smooth progress of the alliance. In order to make up for the above shortcomings, this paper proposes an improved Shapley value method based on ANP method on the basis of considering the different effects of various impact factors. In this method, we use the ANP model to determine the extent of the effects of each impact factor, which improve the Shapley value method based on the same specific gravity correction.

In a n-player game, combined with the particularity of power commodities, we can see that there are two main factors in the power market: the level of investment and the ability to innovate. The level of input of the players is $\left\{\rho_{1}, \rho_{2}, \ldots, \rho_{n}\right\}$, and the set of innovation ability is $\left\{\mu_{1}, \mu_{2}, \ldots, \mu_{n}\right\}$. Among them, the greater the degree of input, the weaker the willingness of participants to participate in cooperation, and the participants will receive compensation. The elements of the collection of innovation ability represent the technical innovation ability of the participants. The greater the technological innovation ability, the stronger the willingness of the players to participate in cooperation, and the advantages in the game process are more obvious, and the participants will therefore compensate. This ensures the smooth progress of cooperation. In the traditional Shapley value method, the elements of these sets are all $\frac{1}{n}$, which is inconsistent with the environment in the real bilateral trading market.

This paper considers that the compensation rate of input level can be expressed as $\nabla \rho_{i}=\rho_{i}-\frac{1}{n}, i \in$ $\{1,2, \ldots, n\}$, and obviously there is $\sum_{i=1}^{n} \rho_{i}=0$. If $\nabla \rho_{i}>0$, it means that the input of participant $i$ is higher than the average input of the person in the game, and its willingness to build a certain alliance will be relatively low. Therefore, if he does not mention the profits he has allocated at this time, he will take the initiative of not joining the alliance to compel the members who are willing to participate in the alliance to compromise, so as to maximize their own interests; When $\nabla \rho_{i}<0$, participant $i$ must take out some of the benefits to compensate the players who are facing higher levels of input, thus ensuring the stability of the alliance, making it more profitable than the individual action. Similarly, the compensation function of technological innovation capability is $\nabla \mu_{i}=\mu_{i}-\frac{1}{n}$, which is the same as the input degree compensation function, $\sum_{i=1}^{n} \nabla \mu_{i}=0$.

The input index and the innovation function's action index obtained from the AHP (Analytic Network Process) model evaluation result are $\alpha$ and $\beta$, respectively, and the compensation coefficient of the final distribution of all impact factors is shown in Equation (18). The amount of correction for each person in the league can be obtained as shown in Equation (19), and the improved cooperative profit formula is shown in Equation (20).

$$
\begin{gathered}
\nabla B_{i}=\alpha \nabla \rho_{i}+\beta \nabla \mu_{i} \\
\alpha+\beta=1 \\
\nabla \phi_{i}(V)=\nabla B_{i} \sum_{i=1}^{n} \phi_{i}(V) \\
\phi_{i}^{(1)}(V)=\phi_{i}(V)+\nabla \phi_{i}(V)
\end{gathered}
$$


when $\nabla B_{i}=0, \nabla \phi_{i}(V)=0, \phi_{i}^{(1)}(V)=\phi_{i}(V)$, that is, no subsidy. That is to say, the traditional Shapley value method is a special case when $\nabla B_{i}=0$.

When the characteristics of the market environment and alliance members change, the factors affecting bilateral transactions may increase (more than two), but these factors can be dealt with according to the above methods, and the game process of benefit distribution can be corrected to ensure smooth transactions.

\section{Case Analysis}

\subsection{Analysis of the Benefit Distribution of Wind Power Transactions Based on Kernel Method}

\subsubsection{One-to-Many Trading Mode}

In the one-to-many trading mode, according to the green certificate system implemented by the state, in order to ensure the continuous operation of the wind power plant, the price of the wind power plant is $0.3 \mathrm{RMB} / \mathrm{kWh}$, and the power $\mathrm{Q}$ that the wind power plant can provide is 200 million $\mathrm{kWh}$. Assuming that there are 4 purchasers $\left\{B_{1}, B_{2}, B_{3}, B_{4}\right\}$ competing, considering the state's subsidies for renewable energy and the green certificate system, the price quoted by purchaser $B$ is $\{0.35,0.376$, $0.4,0.28\}(\mathrm{RMB} / \mathrm{kWh})$. Alliance $L=\left\{A, B_{1}, B_{2}, B_{3}, B_{4}\right\}^{\prime}$ 's quote collection is $P=\{0.3,0.35,0.37,0.4,0.28\}$. The profit of cooperation between generator $A$ and purchaser $B_{i}$ is shown in Equation (21). Because $P_{B_{4}}=0.28<P_{A}$, the purchaser $B_{4}$ does not participate in the contract transaction, $\pi_{4}=0$. The total profit of the generator $A$ and the purchaser $B_{i}$ is shown in Equation (22). The distribution of benefits according to the nucleolar method can be transformed into an optimization problem as shown in Equation (23).

$$
\begin{gathered}
\pi_{1}=\left(P_{B_{1}}-P_{A}\right) Q=(0.35-0.3) * 20000=1000 \\
\pi_{2}=\left(P_{B_{2}}-P_{A}\right) Q=(0.37-0.3) * 20000=1400 \\
\pi_{3}=\left(P_{B_{3}}-P_{A}\right) Q=(0.4-0.3) * 20000=2000 \\
\pi=\max \pi_{i}=2000 \\
i \in\{1,2,3,4\}
\end{gathered}
$$

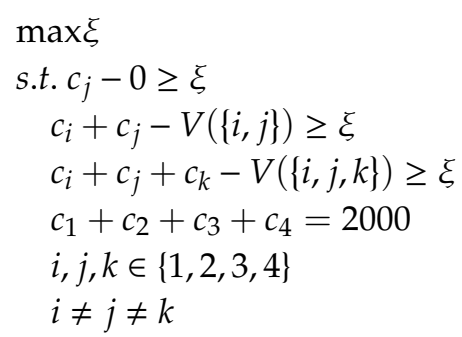

Among them, $c_{1}, c_{2}, c_{3}, c_{4}$ are the benefit distribution values of alliance members $1,2,3$, and 4 , respectively.

The MATLAB software (R2014a, The MathWorks, Inc, Natick, MA, USA) can be used to solve the optimization problem as shown in Equation (23). The solution result is $c_{1}=1554, c_{2}=0, c_{3}=0$, $c_{4}=446$. The generator $A$ will cooperate with the purchaser $B_{3}$, and the formula for calculating the contract electricity price is shown in Equation (24).

$$
\left\{\begin{array}{l}
(P-0.3) * 20000=1554 \\
(0.4-P) * 20000=446
\end{array}\right.
$$

After signing the transaction contract, the generator can obtain the interest of 15.54 million. The purchaser can obtain 4.46 million benefits, and the formula for calculating the contract electricity price is shown in Equation (24). The contracted electricity price $P=0.3777 \mathrm{RMB} / \mathrm{kWh}$. At this time, both the power producer and the purchaser can obtain the maximum benefit and achieve the Pareto 
optimality. In the non-cooperative game relationship, since the purchaser $B_{3}$ offers the highest price, the generator $A$ will directly cooperate with $B_{3}$ at an electricity price of $0.4(\mathrm{RMB} / \mathrm{kWh})$. Although the generating business gains the most at this time, it also increases the purchasing cost of $B_{3}$, which is not conducive to a fair transaction.

\subsubsection{Many-to-Many Trading Mode}

When there are multiple power suppliers and purchasers in the trading market, the many-to-many trading mode should be selected. At this time, the electricity suppliers are set to $\left\{A_{1}, A_{2}\right\}$ and the electricity suppliers are set to $\left\{B_{1}, B_{2}, B_{3}\right\}$. The power suppliers and the purchasers will jointly make a quotation and determine the distribution of benefits, cooperation partners and cooperative electricity prices through the nucleolus method. Under the premise of comprehensive consideration of national renewable energy subsidies and green power certificates, the set of quotations of alliance members is $P=\left\{P_{A_{1}}, P_{A_{2}}, P_{B_{1}}, P_{B_{2}}, P_{B_{3}}\right\}=\{0.4,0.3,0.5,0.4,0.3\}$ (RMB/kWh). For the convenience of calculation, the electricity provided by the power supplier $\left\{A_{1}, A_{2}\right\}$ is $\{1500,1000\}(10,000 \mathrm{kWh})$, purchaser $\left\{B_{1}, B_{2}, B_{3}\right\}$ 's willingness to purchase is $\{1500,800,500\}(10,000 \mathrm{kWh})$. A single partner cannot meet the power needs or supply capabilities of any trader, so the trader will choose to trade with multiple partners at the same time. From the above data, the profit that can be obtained by the alliance $\left\{A_{1}, B_{1}\right\}$ is shown in Equation (25). The benefits that can be obtained by other cooperative trading methods are shown in Equation (26).

$$
\begin{gathered}
\pi_{A_{1} B_{1}}=\left(P_{B_{1}}-P_{A}\right) * Q_{A_{1} B_{1}}=(0.5-0.4) * 1500=150 \\
\pi_{A_{1} B_{1} B_{2}}=150, \pi_{A_{1} B_{1} B_{3}}=150, \pi_{A_{1} B_{2} B_{3}}=150 \\
\pi_{A_{2} B_{1}}=200, \pi_{A_{2} B_{2}}=80, \pi_{A_{2} B_{1} B_{2}}=200, \pi_{A_{2} B_{1} B_{3}}=200, \pi_{A_{2} B_{2} B_{3}}=80, \pi_{A_{2} B_{1} B_{2} B_{2}}=200 \\
\pi_{A_{1} A_{2} B_{1}}=250, \pi_{A_{1} A_{2} B_{2}}=80, \pi_{A_{1} A_{2} B_{1} B_{2}}=250, \pi_{A_{1} A_{2} B_{1} B_{3}}=250, \pi_{A_{1} A_{2} B_{2} B_{3}}=80
\end{gathered}
$$

Using MATLAB software to solve the above optimization problem can get the benefit distribution result shown in Formula (27).

$$
\begin{aligned}
& c_{1}^{\prime}=37.01 \\
& c_{2}^{\prime}=89.5 \\
& c_{3}^{\prime}=123.49 \\
& c_{4}^{\prime}=c_{5}^{\prime}=0
\end{aligned}
$$

According to the principle of matching the price, the final cooperation result is that the contract quantity of electricity of $A_{1}$ and $B_{1}$ is 5 million $\mathrm{kWh}$, and the contract quantity of electricity of $A_{2}$ and $B_{1}$ is 10 million $\mathrm{kWh}$. The profit distribution result is brought into the profit Formula (12) to obtain the contract price calculation formula for bilateral transactions as shown in Formula (28).

$$
\left\{\begin{array}{l}
\left(P_{A_{1} B_{1}}-P_{A_{1}}\right) \times Q_{A_{1} B_{1}}=\left(P_{A_{1} B_{1}}-0.4\right) \times 500=37.01 \\
\left(P_{A_{1} B_{1}}-P_{A_{2}}\right) \times Q_{A_{2} B_{1}}=\left(P_{A_{2} B_{1}}-0.3\right) \times 1000=89.5 \\
\left(P_{B_{1}}-P_{A_{1} B_{1}}\right) \times Q_{A_{1} B_{1}}+\left(P_{B_{1}}-P_{A_{2} B_{1}}\right) \times Q_{A_{2} B_{1}}=\left(0.5-P_{A_{1} B_{1}}\right) \times 500+\left(0.5-P_{A_{2} B_{1}}\right)=123.49
\end{array}\right.
$$

The final game results of generator $A_{1}$ and $A_{2}$ and purchaser $B_{1}$ are shown in Table 1.

Table 1. The final game results.

\begin{tabular}{cccc}
\hline Generator & $\begin{array}{c}\text { Contract Price } \\
\text { (RMB/kWh) }\end{array}$ & $\begin{array}{c}\text { Contract Quantity of } \\
\text { Electricity (million/kWh) }\end{array}$ & $\begin{array}{c}\text { Purchase Cost } \\
\text { (million/kWh) }\end{array}$ \\
\hline$A_{1}$ & 0.474 & 500 & 237 \\
$A_{2}$ & 0.39 & 1000 & 390 \\
\hline
\end{tabular}

In this many-to-many trading mode, if the previous non-cooperative game pricing is adopted, $B_{1}$ will purchase electricity from the power supplier $A_{1}$ and $A_{2}$ respectively. At this time, the purchase cost is $0.3 \times 1000+0.4 \times 500=500$ million $/ \mathrm{kWh}$, which is much higher than the purchase cost under 
the cooperative game relationship (Table 1). Therefore, it cannot meet the demands of both parties to maximize their interests, which is not conducive to the sustainable development of the enterprise.

From the results of the above two examples, it can be found that the bilateral transaction mode can achieve the Pareto optimal principle of individual rationality and collective level while ensuring the smooth operation of the alliance, which is in line with the actual situation. On the other hand, when using the nucleolus method to distribute benefits, it fully considers the interests of both the supply and demand sides, and ensures that the participants in the multiplayer cooperative game can obtain the maximum benefit even in the worst case. In general, this model is very suitable for the wind power trading market.

\subsection{Analysis of Wind Power Transaction Cases Based on ANP and Shapley Values}

By reading the literature, we found that when it comes to the interests of the assignment problem, the scholars generally use the Shapley value for both parties undertaking profit allocation, but because of wind power generation is different from thermal power, it has a lot of uncertainty, so in the process of a wind power transaction need to fully consider the possible risk, the investment degree, and the innovation ability of both parties. At present, considering the wind cooperative game pricing research is less widely available, on the basis of the original Shapley value, this paper builds a wind cooperative game based on ANP and the Shapley value for a profit allocation mechanism. On the premise of considering the national renewable energy subsidy policy and green power certificate, it is assumed that the transaction risks of the cooperation between the power generator $A$ and the electricity purchaser $\left\{B_{1}, B_{2}, B_{3}, B_{4}\right\}$ are $\{15 \%, 15 \%, 20 \%$ and $50 \%\}$, respectively. As the threshold of acceptable risk is $50 \%$, supplier $A$ will decide to enter into bilateral trading contracts with $\left\{B_{1}, B_{2}, B_{3}\right\}$ at the same time. According to Equation (14), the contract quantity of electricity of $A$ and $\left\{B_{1}, B_{2}, B_{3}\right\}$ are $\frac{4}{11} Q, \frac{4}{11} Q$ and $\frac{3}{11} Q$, respectively. For the convenience of calculation, set the power supplier $A$ can provide is 11 million $\mathrm{kWh}$. Obviously, the greater the risk of cooperation with the purchaser $A$, the smaller the contracted quantity of electricity. The power supplier $A$ decide the electricity that the bilateral transaction contracts signed with $\left\{B_{1}, B_{2}, B_{3}\right\}$ are 4,4 , and 3 million $\mathrm{kWh}$, respectively. Let the quotation set $\left\{P_{A^{\prime}}^{\prime}, P_{B_{1}}^{\prime}, P_{B_{2}}^{\prime}, P_{B_{3}}^{\prime}\right\}$ of $A$ and $\left\{B_{1}, B_{2}, B_{3}\right\}$ be $\{0.3,0.32,0.32,0.35\}$ (RMB/kWh), then the profit of the supplier $A$ and $B_{1}$ can be as shown in Formula (29).

$$
V\left(A B_{1}\right)=\left(P_{B_{1}}^{\prime}-P_{A}^{\prime}\right) * Q_{A B_{1}}=(0.32-0.3) \times 400=8
$$

Similarly, we can get other ways of cooperation: $V\left(A B_{2}\right)=8, V\left(A B_{3}\right)=15, V\left(A B_{1} B_{2}\right)=16$, $V\left(A B_{1} B_{3}\right)=23, V\left(A B_{2} B_{3}\right)=23, V\left(A B_{1} B_{2} B_{3}\right)=8$. Using Formulas (15) and (17), the distribution profits of members of the alliance and the transaction prices between the electricity supplier $A$ and the purchaser $B_{1}, B_{2}$ and $B_{3}$ can be obtained as shown in Table 2

Table 2. The distribution of profits among union members.

\begin{tabular}{ccccc}
\hline Union Members & $\boldsymbol{A}$ & $\boldsymbol{B}_{1}$ & $\boldsymbol{B}_{2}$ & $\boldsymbol{B}_{3}$ \\
\hline Distribution profit & 15.5 & 4 & 4 & 7.5 \\
Transaction price & $/$ & 0.31 & 0.31 & 0.325 \\
\hline
\end{tabular}

Since the game of bilateral transactions is affected by the level of investment and innovation of alliance members, it is necessary to improve on the basis of the Shapley value. Set the parameters of the alliance members as shown in Table 3. 
Table 3. Related parameters of alliance members.

\begin{tabular}{cccccc}
\hline Parameters & Description & $\boldsymbol{A}$ & $\boldsymbol{B}_{1}$ & $\boldsymbol{B}_{2}$ & $\boldsymbol{B}_{3}$ \\
\hline$\rho$ & Investment degree & $1 / 6$ & $1 / 6$ & $1 / 2$ & $1 / 6$ \\
$\mu$ & Innovation ability & $1 / 3$ & $1 / 6$ & $1 / 6$ & $1 / 3$ \\
$\nabla \rho$ & The compensation rate of investment degree & $-1 / 12$ & $-1 / 12$ & $1 / 4$ & $-1 / 12$ \\
$\nabla \mu$ & The compensation rate of innovation ability & $1 / 12$ & $-1 / 12$ & $-1 / 12$ & $1 / 12$ \\
\hline
\end{tabular}

Let $\alpha=1 / 3, \beta=2 / 3$, we can get the correction coefficient as $\nabla B=\{1 / 36,-3 / 36,3 / 36,1 / 36\}$. The above example is modified according to the correction coefficient and formula 19. Finally, the corrected profit and contract price can be obtained, as shown in Table 4.

Table 4. Revised results for Union members.

\begin{tabular}{ccccc}
\hline Union Members & $\boldsymbol{A}$ & $\boldsymbol{B}_{1}$ & $\boldsymbol{B}_{2}$ & $\boldsymbol{B}_{3}$ \\
\hline Revised Profit & 16.36 & 1.42 & 4.86 & 8.36 \\
\hline Revised Electricity Price & $/$ & 0.316 & 0.308 & 0.322 \\
\hline
\end{tabular}

The comparison chart before and after the establishment of the profit correction visually shows the impact of the introduction of the investment level and the innovation ability index on the profit of both parties, as shown in Table 5 .

Table 5. Comparison of profit distribution.

\begin{tabular}{ccccc}
\hline Union Members & $\boldsymbol{A}$ & $\boldsymbol{B}_{1}$ & $\boldsymbol{B}_{2}$ & $\boldsymbol{B}_{3}$ \\
\hline Before Correction & 15.5 & 4 & 4 & 7.5 \\
After Correction & 16.36 & 1.42 & 4.86 & 8.36 \\
\hline
\end{tabular}

As can be seen from Tables 4 and 5 , since the input of the power supplier $A, B_{1}$ and $B_{3}$ is small, but the value that can be created is high, so $B_{2}$ can receive compensation from members $A, B_{1}$, and $B_{3}$. At the same time, because the innovation ability of $A$ and $B_{3}$ is stronger than that of $B_{1}$ and $B_{2}, B_{1}$ and $B_{2}$ need to give part of the profit compensation to $A$ and $B_{3}$ to ensure the smooth cooperation. In addition, since the impact of the investment level on the profit distribution result is relatively smaller than that of the innovation ability, the profit distribution value of the power supplier $A$ and the electricity purchaser $B_{3}$ under the combined influence factors increases. Moreover, since $B_{1}$ is weak in terms of input level and innovation ability, it needs to make relatively more profits to compensate other participants to ensure the smooth progress of cooperation. $B_{2}$ has obtained a certain amount of profit distribution value because of its greater advantage in the degree of investment.

At present, most of the existing models for wind power pricing only consider the marginal cost and demand of wind power generation, and cannot fully consider other factors that affect its revenue. This paper uses the nucleolus method to simulate the contract price determination mechanism based on transaction object selection, and forms a distribution scheme for sympathy and protection of vulnerable groups. For the profit sharing scheme, this paper proposes that the modified Shapley value method has its pertinence, practicability and feasibility for the contract price determination mechanism under the influence of multiple influencing factors. By emphasizing the marginal contribution and taking into account the needs of all parties to the transaction, it is more reasonable and effective than the existing profit sharing scheme.

\section{Conclusions}

This paper first analyzes the relatively mature power trading modes at home and abroad, and believes that the power bilateral trading market can quickly reflect changes in market demand, 
which is more conducive to reducing costs and improving efficiency. It is an important direction for China's power trading reform. Secondly, based on the theory of nucleolus, we comprehensively explore the strategic choices and benefits of both parties in power trading under various circumstances and the market price of wind power. Finally, an improved Shapley value method considering transaction risk, company investment, and innovation ability is proposed to study the benefit distribution problem in cooperative games. In the case of considering the characteristics of alliance members, the ANP method is used to adjust the benefit distribution results. Through case analysis, it can be verified that this pricing model can effectively take into account the interests of both parties in the transaction, so that both parties can reach the Pareto optimal state. The main findings are as follows:

(1) The use of the nucleolus method for the distribution of benefits, which fully considers the interests of both the supply and demand sides, ensures that the participants in the multiplayer cooperative game can also obtain the maximum benefit in the most unfavorable situation.

(2) Based on the improved Shapley value profit sharing method, transaction risk, company investment level and innovation ability can be effectively considered in the process of profit distribution. This allows companies with lower trading risks, more capital investment, and stronger technological innovation capabilities in cooperative competition to get more profits.

Based on the above analysis, the following suggestions are given:

(1) Guide wind power companies to actively participate in market and scientific quotations. It can be seen from the analysis in this paper that members participating in the transaction can obtain more reasonable benefits, and wind power enterprises should be encouraged to actively participate in the transaction, as the quotation of both parties directly affects the transaction result. Scientific quotation can avoid risks and maximize profits.

(2) Actively promote trade reform of power companies, and grasp the direction of reform according to the actual situation of enterprises. The bilateral trading market studied in this paper is very suitable for the Chinese wind power market. However, at present, the price of wind power implemented in China is still set by the government departments, and the reform of market-based pricing will be implemented in 2019. Therefore, further theoretical exploration of the bilateral trading market is of great significance to the long-term impact of wind power generation in China. This will be the topic for our main work.

Author Contributions: The manuscript was written through contributions of all authors. All authors have given approval to the final version of the manuscript, and all authors contributed equally. Data curation, X.D.; Methodology, X.D. and F.D.; Resources, F.D.; Software, X.D.; Supervision, F.D.; Writing-original draft, X.D.; Writing-review \& editing, F.D. and L.S.

Funding: This research was funded by The National Social Science Fund of China (19BJY074).

Acknowledgments: The authors would like to thank the anonymous referees and the editor of this journal.

Conflicts of Interest: The authors declared that they have no conflicts of interest to this work.

\section{References}

1. Osorio, G.J.; Shafie-Khah, M.; Soares, N.G.S.; Catalao, J.P.S. Optimal Dynamic Tariffs for Flexible Ramp Market in the Presence of Wind Power Generation and Demand Response. In Proceedings of the 2018 IEEE International Conference on Environment and Electrical Engineering and Industrial and Commercial Power Systems Europe (EEEIC/I\&CPS Europe), Palermo, Italy, 12-15 June 2018.

2. Fang, X.; Hodge, B.; Du, E.; Kang, C.; Li, F. Introducing Uncertainty Components in Locational Marginal Prices for Pricing Wind Power and Load Uncertainties. IEEE T Power Syst. 2019, 34, 2013-2024. [CrossRef]

3. Gersema, G.; Wozabal, D. An Equilibrium Pricing Model for Wind Power Futures. Energy Econ. 2017, 65, 64-74. [CrossRef]

4. Bolinger, M.; Wiser, R. Wind power price trends in the United States: Struggling to remain competitive in the face of strong growth. Energy Policy 2009, 37, 1061-1071. [CrossRef] 
5. Hitaj, C. Wind power development in the United States. J. Environ. Econ. Manag. 2013, 65, $394-410$. [CrossRef]

6. Munksgaard, J.; Morthorst, P.E. Wind power in the Danish liberalised power market-Policy measures, price impact and investor incentives. Energy Policy 2016, 36, 3940-3947. [CrossRef]

7. Tomiyama, K.; Kawano, Y.; Hashimoto, T.; Ohtsuka, T. Real-time price optimization for load frequency control in electric power systems with wind farms. In Proceedings of the 2016 SICE International Symposium on Control Systems (ISCS), Nagoya, Japan, 7-10 March 2016.

8. Bruck, M.; Sandborn, P.; Goudarzi, N. A Levelized Cost of Energy (LCOE) model for wind farms that include Power Purchase Agreements (PPAs). Renew. Energy 2018, 122, 131-139. [CrossRef]

9. Pircalabu, A.; Hvolby, T.; Jung, J.; Hog, E. Joint price and volumetric risk in wind power trading: A copula approach. Energy Econ. 2017, 62, 139-154. [CrossRef]

10. Sarfati, M.; Hesamzadeh, M.R.; Biggar, D.R.; Baldick, R. Probabilistic pricing of ramp service in power systems with wind and solar generation. Renew. Sustain. Energy Rev. 2018, 90, 851-862. [CrossRef]

11. Dai, Z.; Wu, Z. Reactive Power Pricing Model Considering the Randomness of Wind Power Output. IOP Conf. Ser. Earth Environ. Sci. 2018, 108, 52004. [CrossRef]

12. Benth, F.E.; Pircalabu, A. A non-Gaussian Ornstein-Uhlenbeck model for pricing wind power futures. Appl. Math. Financ. 2018, 25, 36-65. [CrossRef]

13. Wang, Y.; Zhao, Y. Analysis and Suggestions on China's Wind Power Price Policy. Power Demand Side Manag. 2007, 9, 15-17.

14. Zhang, Z.; Xie, H.; Wang, B. Analysis of Wind Power Price and Policy Suggestions. China Electr. Power 2001, $34,44-48$.

15. Ping, X. Discussion on On-grid Electricity Price of Wind Power. J. Zhejiang Univ. Water Resour. Telecommun. 2001, 13, 44-46.

16. Li, H.; Xiao, J. Preliminary Analysis of Global Wind Power Costs. Sol. Energy 2005, 3, 45-48.

17. Song, Y. Ten Factors Affecting the Formation of Wind Power Price Mechanism. Chin. Foreign Entrep. 2010, 4, 189-190.

18. Dong, F.; Shi, L. Regional differences study of renewable energy performance: A case of wind power in China. J. Clean. Prod. 2019, 233, 490-500. [CrossRef]

19. Sun, L. Economic Cost Evaluation Model and Application Research of Wind Power Enterprises; North China Electric Power University: Beijing, China, 2010.

20. Li, Y. Analysis of Wind Power Cost Factors and Related Industrial Policy Research in China; North China Electric Power University: Beijing, China, 2011.

21. Dong, F.G.; Shi, L.; Ding, X.; Li, Y.; Shi, Y. Study on China's Renewable Energy Policy Reform and Improved Design of Renewable Portfolio Standard. Energies 2019, 12, 2147. [CrossRef]

22. Wang, Z.; Lu, Z. Research on the Formation Mechanism of Wind Power Online Price in China. Price Theory Pract. 2008, 9, 54-55.

23. Qiuju, Z.; Guangwen, M.; Wei, C.; Zhang, Q.; Ma, G.; Chen, Y. Discussion on Green On-grid Price Mechanism. Hydroelectr. Power 2009, 35, 1-4.

24. Liu, J.; Liu, T.; Cui, C. Wind Power Pricing Mechanism Based on Wind Power Cost and Thermal Power Profit. China Electr. Power 2015, 48, 89-94. [CrossRef]

25. Gao, X. Experience and inspiration of Australian interstate transmission pricing. Wind Sci. Technol. 2016, 10, 113.

26. Yang, L. Research on price mechanism of renewable energy power generation under market-oriented reform. China Electr. Power 2016, 49, 119-122.

27. Yin, S.; Shi, D. Research on pricing mechanism of British nuclear power. China Energy 2017, 39, 33-37.

28. Su, M. Power marketing model and new price system under new situation. SME Manag. Technol. 2018, 7, 33-34.

29. Wang, Y.; Meng, J.; Sun, L. Research on Pricing Mechanism of Peak and Valley Electricity Price Based on Wind Power Consumption. Price Theory Pract. 2018, 10, 53-56.

(C) 2019 by the authors. Licensee MDPI, Basel, Switzerland. This article is an open access article distributed under the terms and conditions of the Creative Commons Attribution (CC BY) license (http://creativecommons.org/licenses/by/4.0/). 